\title{
Temperature-dependence of $\mathrm{Mg} / \mathrm{Ca}$ Deposition in Keratoisis sp.
}

\author{
C. M. MacRae ${ }^{1}$, N. C. Wilson ${ }^{1}$, R. Thresher ${ }^{2}$ and R. Gurney ${ }^{2}$ \\ ${ }^{1}$ Microbeam Laboratory, CSIRO Minerals, Clayton, Vic., Australia \\ ${ }^{2}$ CSIRO Marine Research, Hobart, Tasmania, Australia
}

Magnesium/calcium ratios in the calcite skeletons of long-lived (300-500 years) deep-water gorgonian corals (Keratoisis $\mathrm{sp}$ ) have been speculated to vary as a function of ambient water temperature at the time the carbonate was deposited. We tested this hypothesis by doing parallel analyses within the same coral for $\mathrm{Mg} / \mathrm{Ca}$, a nominally independent temperature marker. Secondly we compared the composition of the outer margin of a Keratoisis sp. with a four-year time series of daily temperature records collected at a nearby moored deep-ocean instrument array. There is a good fit between the $\mathrm{Mg} / \mathrm{Ca}$ trajectory and the recorded data. $\mathrm{Mg} / \mathrm{Ca}$ ratios at the margin of the coral also correlate with and appear to track temperatures measured at about 1000 meters, at a scale within the coral that is consistent with its age (as inferred from counts of apparent annual growth increments and radiometric techniques) and its date of collection. Growth banding is evident in a map collected in a direction of edge-to-core of a coral, of which the outer region is shown in Figure 1. The accompanying $\mathrm{Mg} / \mathrm{Ca}$ profile across the same region is overlaid.

The microanalysis of the Keratoisis sp. was performed on polished sections cut through the stem of the coral, close to the base to maximise the size of each section. Typically, each Keratoisis sp. section was 5 centimetres in diameter and polished with a final lap of 1 micron diamond paste. Measured weight-fractions for $\mathrm{Mg}, \mathrm{Sr}$ and $\mathrm{Ca}$ were significantly higher in the fine scale analyses (5 $\mu \mathrm{m}$ spot and 7-10 nA beam current) than they were in the coarse analysis $(50 \mu \mathrm{m}$ spot and $50 \mathrm{nA}$ beam current) of the same coral. All analyses were performed at $15 \mathrm{kV}$ on a JEOL $8900 \mathrm{R}$ Superprobe with $\mathrm{Mg}$ and $\mathrm{Sr}$ measured by wavelength dispersive spectrometry while $\mathrm{Ca}$ was measured by energy dispersive spectrometry. To improve the counting statistics of $\mathrm{Mg}$ x-rays two spectrometers were employed. Previous work on biogenic carbonates in fishes (otoliths) suggested the difference in fine and coarse scale analyses was due to the large effect of heating at the high beam power density (BPD) required for the $5 \mu \mathrm{m}$ analyses [1]. We tested this hypothesis in the coral calcite by comparing the apparent weight-fractions of $\mathrm{Mg}, \mathrm{Sr}$ and $\mathrm{Ca}$ as measured using 5 different BPDs in an area of coral that was visually relatively homogeneous. For the comparison, 33 replicates of each BPD were randomly allocated onto a grid in the sampled area. Beam power densities were varied by altering beam diameters from 5 to $50 \mu \mathrm{m}$ and beam currents from 15 to 70 nA. As expected, based on Gunn et al. (1992), apparent weight-fractions differed significantly as a function of BPD for all three elements (ANOVA Mg F $\mathrm{F}_{4,160}=86.4$; $\mathrm{Sr} \mathrm{F}_{4,160}=26.7$; $\mathrm{Ca} \mathrm{F}_{4,160}=112.9$, $\mathrm{p}$ $<0.0001$ ), being highest at intermediate BPDs. To identify the uniformity of growth within each section magnesium, strontium, and calcium x-ray maps of corals were collected, Figure 1. Generally the growth over tens of years is uniform however shorter intervals reveal complex growth conditions which may reflect seasonal changes.

The correlation between ambient water temperature and $\mathrm{Mg} / \mathrm{Ca}$ ratios indicates it is possible to resolve annual and longer term variability in water temperature at depths in excess of 800 meters from the gorgonians [2]. We have begun to apply this method to reconstruct paleo-oceanography in the Australian and New Zealand region over the last 3-4 centuries. Initial results indicate a long- 
term cooling trend along the coast, overlaid by apparent 7-11 year and 40-60 year periodicities in water temperature. These oceanographic patterns appear to reflect regional climatology, and provide an historical context for understanding recent changes in climate and oceanography and for testing the current generation of coupled ocean-atmosphere climate models.

References

[1] Gunn et al. (1992). Journal of Experimental Marine Biology and Ecology, 158: 1-36.

[2] Thresher et al. (2006). Bulletin of Marine Science (in press).

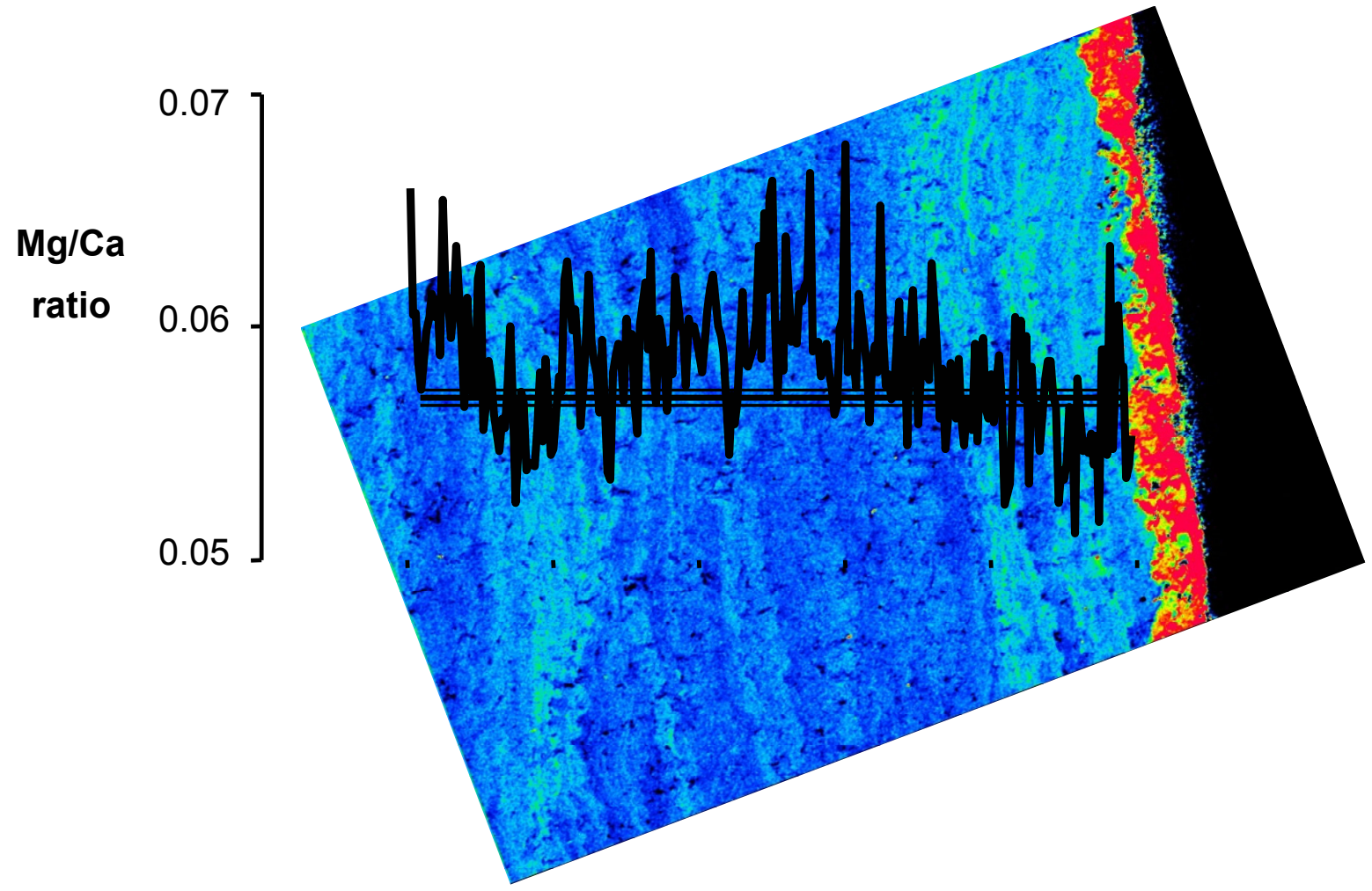

Figure 1. Comparison of quantitative analyses for $\mathrm{Mg} / \mathrm{Ca}$ ratio in Keratosis sp., measured using a contiguous $5 \mu \mathrm{m}$ beam spots (irregular dark line), overlaid onto a $\mathrm{Mg} / \mathrm{Ca}$ map for the same region. The position of the quantitative analysis line is shown by the multiple horizontal lines. 